\title{
Local Anaesthetic Efficacy of $4 \%$ Articaine for Inferior Alveolar Nerve Block and Buccal Infiltration in Teeth with Irreversible Pulpitis - A Randomized, Double-Blind Clinical Trial
}

\author{
Pradeep Kumar Buggaveeti ${ }^{1}$, Sirisha Kantheti² ${ }^{2}$ Jyothi Mandava ${ }^{3}$, Ravi Kumar Konagala ${ }^{4}$, \\ Ramesh Penumaka5, Bhargav Kambhampati6
}

\begin{abstract}
1, 6 Department of Conservative Dentistry and Endodontics, Mamatha Dental College and Hospital, Khammam, Telangana, India., 2, 3, 4 Department of Conservative Dentistry and Endodontics, GITAM Dental College and Hospital, Visakhapatnam, Andhra Pradesh, India. ${ }^{5}$ Department of Conservative Dentistry and Endodontics, Drs Sudha \& Nageswara Rao Siddhartha Institute of Dental Sciences, Vijayawada, Andhra Pradesh, India.
\end{abstract}

\section{ABSTRACT}

\section{BACKGROUND}

Achieving profound pulpal anaesthesia with an inferior alveolar nerve block (IANB) in lower molars suffering irreversible pulpitis is difficult and quite challenging. In many instances, supplemental anaesthesia is required during endodontic therapy. The present study was done to evaluate the efficiency of $2 \%$ lidocaine and $4 \%$ articaine comparatively, as an inferior alveolar nerve block (IANB) and supplemental infiltration buccally in providing complete mandibular molar anaesthesia.

\section{METHODS}

This is a randomized double-blinded study. Sixty patients were categorized randomly into test group $(n=30)$ and control group $(n=30)$. Patients in the test group were anaesthetized with $4 \%$ articaine (1:100,000 epinephrine dilution), and those in the control group were anaesthetized with $2 \%$ lidocaine $(1: 80,000$ epinephrine dilution). The Heft-Parker visual analog scale (HP-VAS) was utilized for rating patient's pain during the treatment procedure. In case of pain after IANB, a supplemental buccal infiltration was given with the same anaesthetic used for IANB. Complete pain absence or mild pain was regarded as an anaesthetic efficacy, and moderate to severe pain was regarded as an anaesthetic failure. Recorded data was analyzed using the chi-square test and two proportion $\mathrm{Z}$ test. The set significance level was 0.05 .

\section{RESULTS}

After an IANB, observed anaesthetic success was $56 \%$ in the articaine (test) group and that in the lidocaine (control) group was $33 \%$. After buccal infiltration, it was $92 \%$ in the articaine group and $75 \%$ in the lidocaine group. The difference was not found significant between the two groups statistically following IANB and infiltration buccally. The overall success of articaine was $96 \%$, and lidocaine was 83 $\%$.

\section{CONCLUSIONS}

Compared to $2 \%$ lidocaine, $4 \%$ articaine was found more efficient in achieving profound pulpal anaesthesia in mandibular molars suffering irreversible pulpitis after IANB and buccal infiltration though the difference was insignificant statistically.

\section{KEY WORDS}

Articaine, Lidocaine, Inferior Alveolar Nerve Block, Buccal Infiltration, Heft-Parker Visual Analog Scale, Irreversible Pulpitis
Corresponding Author:

Dr. Ravi Kumar Konagala,

Reader,

Department of Conservative Dentistry and Endodontics,

GITAM Dental College and Hospital,

Visakhapatnam, Andhra Pradesh, India.

E-mail:dr.ravikumar99@gmail.com

\section{DOI: 10.14260/jemds/2021/535}

How to Cite This Article:

Buggaveeti PK, Kantheti S, Mandava J, et al. Local anaesthetic efficacy of $4 \%$ articaine for inferior alveolar nerve block and buccal infiltration in teeth with irreversible pulpitis - a randomized double-blind clinical trial. J Evolution Med Dent Sci 2021;10(32):2615-2619, DOI: $10.14260 /$ jemds $/ 2021 / 535$

Submission 11-12-2020,

Peer Review 07-07-2021

Acceptance 14-07-2021,

Published 09-08-2021.

Copyright (C) 2021 Pradeep Kumar Buggaveeti et al. This is an open access article distributed under Creative Commons Attribution License [Attribution 4.0 International (CC BY 4.0)] 


\section{BACKGROUND}

Pain management in endodontics is difficult due to pharmacological factors, behavioral factors, practice managing issues.1,2 Pain management can be accomplished by lowering nociceptive input from the injury site, blocking impulses, peripheral nerves, and preventing pain perception within the central nervous system. Blocking the sensitive impulses during root canal procedure is performed with local anaesthesia administration. ${ }^{3}$ Comparatively, deep pulpal anaesthesia in the mandibular teeth is always challenging than maxillary teeth. ${ }^{4}$

IANB is achieved by depositing a local anaesthetic in pterygomandibular space and soaking the inferior alveolar nerve immediately before entering into the mandibular foramen. ${ }^{5}$ Administering local anaesthetic solutions with intermediate duration action by IANB provides pulpal anaesthesia for about one hour in about $85 \%$ of the cases. However, pulpal anaesthesia's success is not guaranteed in all cases and may be compromised by many other factors. ${ }^{6}$ Clinically, studies have shown that failure associated with the IAN block is around $44 \%$ to $81 \% .^{7}$ In cases of inflamed tissues, the success rate of the block is even worse.

Various mechanisms are put forth elucidating the nonfulfillment of local anaesthetics, counting anatomical deviations such as cross and accessory nerve innervations, drop-in regional tissue $\mathrm{pH}$, and excitation of nociceptors like tetrodotoxin or capsaicin-sensitive transient receptor. ${ }^{7}$ Lignocaine hydrochloride is the local anaesthetic that is widely used and labeled as the "gold standard" to compare other local anaesthetic agents. However, failures were reported when lidocaine was administered for achieving an inferior alveolar nerve block. ${ }^{8}$

Many researchers in endodontics had evaluated articaine for its efficacy and safety. ${ }^{9}$ Few studies showed improved success with articaine, whereas others reported the absence of significant difference. Previous studies have compared the anaesthetic efficacy of $2 \%$ lidocaine and $4 \%$ articaine following the IANB in mandibular posterior teeth. But very few studies compared their efficacy after IANB and buccal infiltration (BI) in lower posterior suffering irreversible pulpitis, which will be accomplished in the present study.

\section{METHODS}

This is a randomized double blinded clinical study. Sixty-one patients (both men and women) with an age range of 18 - 55 years, who reported to the Conservative Dentistry and Endodontics Department, at different dental colleges of Andhra Pradesh from January 2019 to December 2019 were chosen for this study. The study protocol was approved by the Joint Research and Ethics Committee of Health University. Patients reporting with a chief complaint of decayed mandibular posterior teeth having mild to severe pain were selected. Past and present symptoms and medical history were noted.

After a thorough clinical examination of the involved tooth, pulp sensitivity was evaluated by thermal tests with endo frost (Coltenewhaledent, Langenau, Germany), heated gutta-percha sticks and electric pulp test (Digitest,
ParkellInc, Edgewood, Newyork, USA). Radiological examination of the involved tooth was performed to assess the periradicular status and anatomical aberrations. Patients who were diagnosed with symptomatic irreversible pulpitis of lower molars with moderate to severe pain were selected. Exclusion criteria of the study were as follows: pulpal necrosis and presence of periapical pathology/radiolucency; patients who had taken pain modifiers within last twelve hours; teeth with periapical radiolucency; patients presenting the history of known allergy and sensitivity to components of local anaesthetic solutions; patients with cardiovascular diseases; pregnant and lactating women; patients presenting lesions clinically at the injection site.

$n=\frac{\left(Z_{1-\frac{\alpha}{2}}^{2}\right) p(1-p)}{E^{2}}$

The sample size was estimated based on the previous data using a formula with $\mathrm{Z}$ value $1.645, \mathrm{E}$ value $0.1, \mathrm{P}$ is 0.7 . Sample size calculated was 28 for each group. As a measure of caution, 70 subjects were enrolled for the study.

Nine subjects were excluded: three subjects due to the age factor, two subjects due to lactation, three subjects due to cardiac disease, and one subject due to oral submucous fibrosis. The remaining 61 volunteers were allocated randomly using the lottery method into two groups: Articaine group ( $n=30)$, Lidocaine group ( $n=31)$ (Fig. 1). After selecting the patient, a consent form that was filled and signed by the patient was collected.

Before administering local anaesthesia, pre-treatment pain was analyzed using the Heft-Parker scale (HP-VAS). Patients were instructed to grade the intensity of their pain on HP-VAS, which is a $170 \mathrm{~mm}$ scale divided into different categories of pain graded as mild, moderate, and severe. Complete pain absence corresponds to $0 \mathrm{~mm}$ reading. The description of slight, weak, faint, and mild pain intensities was correlated to $>0 \mathrm{~mm}$ and till $54 \mathrm{~mm}$ reading. Moderate intensity of pain was correlated to $>54 \mathrm{~mm}$ and till $114 \mathrm{~mm}$ reading. The descriptions of the strong, intense, severe, and maximum amount of pain correlate to $>114 \mathrm{~mm}$ and still 170 mm reading. ${ }^{10}$

The equal number of lidocaine cartridges and articaine cartridges were provided with a code covering the cartridges, making unaware of which cartridge it is. The senior investigator in the operatory was aware of the codes on cartridges, which she gave out randomly in equal numbers as per the groups. As the same anaesthetic was used for block and infiltrations injections, two cartridges with the same code were packed together. Hence, the operator (primary investigator) also was not aware of the anaesthetic that was used. Each patient had received the standard IANB of $2 \%$ lidocaine $(1.8 \mathrm{ml})$ or $4 \%$ articaine $(1.8 \mathrm{ml})$.

Fifteen minutes after administration, patients were asked for subjective symptoms like having lip numbness. Patients who don't have lip numbness were excluded, and their cartridges were replaced. Thus, one patient who had no lip numbness was eliminated. After evaluating the subjective symptoms for profound anaesthesia, rubber dam isolation of the involved tooth was done and preceded to access cavity preparation with a standardized new set of burs for each patient. 
In case of pain, patients were asked to lift their left hand during the procedure so that the operator immediately stops, and patients were instructed to grade the pain over HP visual analog scale throughout the various stages of the therapy - in dentin or pulp space or root canal instrumentation. If the patient does not experience moderate or severe pain following the IANB, it was regarded as a success. The remaining part of endodontic therapy was carried.

For patients with moderate-to-severe pain intensity, the rubber dam frame was removed to administer buccal infiltration with the same anaesthetic solution used for inferior alveolar nerve block. After five minutes of a waiting period, endodontic therapy was carried out. Supplemental buccal infiltration was considered successful as the ability to continue the access preparation, pulpectomy, and root canal instrumentation with no / mild discomfort. In moderate-tosevere pain intensity, as graded over HP-VAS, the buccal infiltration was considered a failure. In those conditions, either the intrapulpal or intraligamentary technique was employed to complete the endodontic therapy. All the pain scale data was recorded, tabulated, and subjected to statistical analysis. Success criteria considered was the absence of moderate or severe pain after endodontic therapy. The access cavity was restored with intermediate restorative material (IRM).

\section{Statistical Analysis}

Data were recorded and transferred to Statistical Package for Social Sciences (SPSS) 22.0 (IBM, Armonk, NY, USA) for statistical analysis. The data were statistically analyzed by using the chi-square test, and intergroup comparison was done using two proportion $\mathrm{Z}$ test.

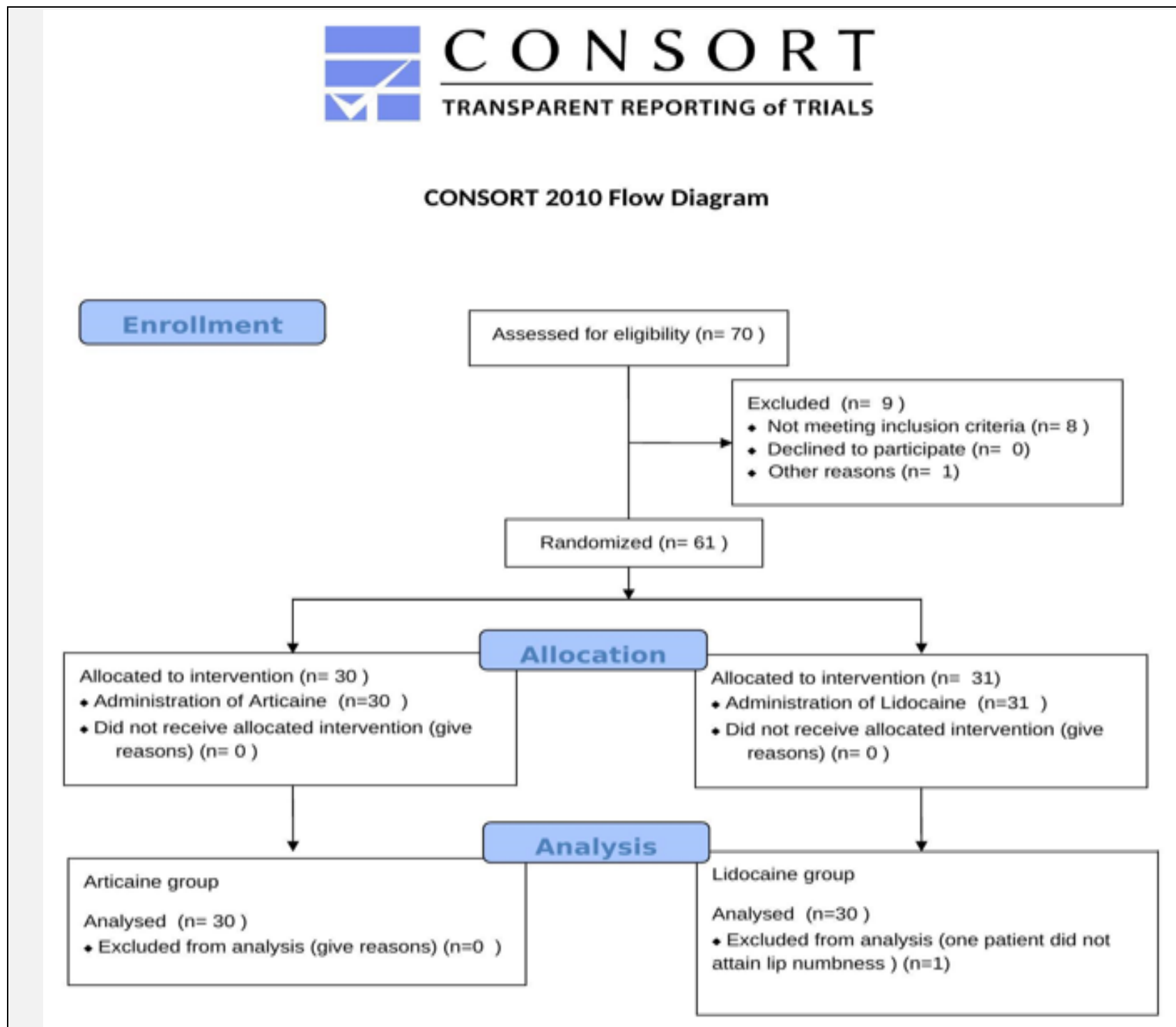

Figure 1. Consort Flow Diagram

\section{RESULTS}

Following an inferior alveolar nerve block, 17 patients $(56.67$ $\%$ ) in the test (articaine) group had mild or no pain intensity during the procedure. In contrast, only ten patients (33.33\%) in control (lidocaine) group had mild or no pain intensity during the procedure (Table1). $\mathrm{Z}$ test revealed a significant difference between two local anaesthetics efficacies after an inferior alveolar nerve block. (Table 2). 
After buccal infiltration, there was mild or no pain in twelve patients $(92.31 \%)$ in the test group and fifteen patients (75\%) in the control group during the procedure (Table 3). Although articaine has a slightly higher success rate, the observed difference between two local anaesthetic agents in the overall success rate for achieving complete anaesthesia during root canal treatment was not statistically significant. (Table4).

\begin{tabular}{|cccc|}
\hline \multicolumn{3}{|c|}{ Group } & Total \\
IANB & Articaine (Test) & Lidocaine (Control) & $27(45 \%)$ \\
Success & $17(56.67 \%)$ & $10(33.33 \%)$ & $33(55 \%)$ \\
Failure & $13(43.33 \%)$ & $20(66.67 \%)$ & $60(100 \%)$ \\
Total & $30(100 \%)$ & $30(100 \%)$ & Chi - sq $3.3000, \mathrm{P}$ - value: 0.069. \\
\hline \multicolumn{3}{|c|}{ Table 1. Comparison between Percentage of Successful Anaesthesia } \\
with IANB Using Articaine and Lidocaine. \\
\hline P $\leq 0.05$ is statistically significant \\
\hline
\end{tabular}

\begin{tabular}{|ccccccc|}
\hline Group & $\mathbf{X}$ & $\mathbf{N}$ & $\mathbf{P}(\mathbf{x} / \mathbf{n})$ & $\mathbf{Z}$ & $\mathbf{P}$ - Value & Decision \\
\hline Articaine (Test) & 17 & 30 & 0.5667 & 1.87 & 0.062 & Not Significant \\
Lidocaine (Control) & 10 & 30 & 0.3333 & 1.8 & & \\
\hline \multicolumn{7}{|c|}{ Table 2. Intergroup Comparison of IANB Success with Articaine and } \\
\hline
\end{tabular}

\begin{tabular}{|cccc|}
\hline Buccal & \multicolumn{3}{c|}{ Group } \\
Infiltration & Articaine (Test) & Lidocaine (Control) & Total \\
Success & $12(92.31 \%)$ & $15(75 \%)$ & $27(81.82 \%)$ \\
Failure & $1(7.69 \%)$ & $5(25 \%)$ & $6(18.18 \%)$ \\
Total & $13(100 \%)$ & $20(100 \%)$ & $33(100 \%)$ \\
\hline Table3. Comparison between Percentage of Successful Infiltration \\
Anaesthesia Using Articaine and Lidocaine \\
\hline \multicolumn{4}{|c}{} \\
\hline
\end{tabular}

\begin{tabular}{|ccccccc|}
\hline Group & $\mathbf{X}$ & $\mathbf{N}$ & $\mathbf{P}$ & $\mathbf{Z}$ & P - Value & Decision \\
Articaine (Test) & 12 & 13 & 0.923 & 1.42 & 0.155 & Not Significant \\
Lidocaine (Control) & 15 & 20 & 0.75 & & & \\
\hline Table 4. Intergroup Comparison of Buccal Infiltration Success with \\
Articaine and Lidocaine
\end{tabular}

\section{DISCUSSION}

Most dental treatments are short-duration procedures and can be performed comfortably under local anaesthesia. Local anaesthetics administered through nerve blocks are regarded as technically more challenging; hence they were less predictable. ${ }^{11,12}$ Patients suffering irreversible pulpitis had a failure rate of local anaesthetic injections as high as eight folds compared to healthy patients.

Inflammatory conditions evoke changes in the pain processing system of central nervous system (CNS). This induces sensitization centrally, leading to increased excitation of central neurons and lowered pain threshold, causing hyperalgesia. Normally local anaesthetic injection blocks $90 \%$ of the nerve fibers successfully, but in conditions of central sensitization, due to exaggerated central nervous system response, even $90 \%$ of nerve fibers blockade may be inadequate in regulating the pain during endodontic therapy, which could be the reason for local anaesthetic failures. ${ }^{11}$ Accessory and cross nerve innervations to the mandibular teeth and patient anxiety might contribute to an inferior alveolar block's failure. ${ }^{13}$ Lidocaine is frequently used amide based local anaesthetic agent with rapid onset of action and combined with epinephrine, provides pulpal anaesthesia for 60 - 90 minutes. ${ }^{14}$
Increased lipid solubility of articaine hydrochloride is due to its thiophene group. The onset of action of articaine is 2 to $2 \frac{1}{2}$ minutes for mandibular block and 1 to 2 minutes for infiltration. ${ }^{15}$

Numbness of lower lip is considered as a good subjective symptom of IANB anaesthesia, although not reliable for the depth of anaesthesia. In the present study, one subject who did not report lip numbness after 15 minutes of anaesthetic agent deposition was excluded from the study. ${ }^{16}$ The endodontic procedure was carried out after 15 minutes of the initial local anaesthetic deposition.

The single operator has administered all local anaesthetics to maintain standardization in administration techniques. Different sizes of burs will have different areas of contact, which results in differences in the amount of heat generation. ${ }^{17}$ hence, standard-sized new bur was used for each patient to standardize the thermal stimulus.

It was observed that the articaine success rate $(56.67 \%)$ was slightly higher than that of lidocaine $(33.33 \%)$ after an inferior alveolar nerve block, which might be attributed to high diffusion of articaine and slightly lower pKa than that of lidocaine. ${ }^{14}$ However, no difference was noted as statistically significant between articaine and lidocaine after IANB. This was similar to previous studies showing a higher success rate with the lidocaine group than the articaine group, though statistically, a significant difference was not there.16,18-21

Buccal infiltration of the same anaesthetic agent was given in cases where the block had failed in gaining pulpal anaesthesia. After the buccal infiltration administration, the articaine success rate was found to be slightly higher than that of lidocaine. This might be due to its rapid diffusion through the buccal cortex. ${ }^{22}$ Statistically, much significant difference was not observed between lidocaine $(75 \%)$ and articaine $(92.31 \%)$ in the present study. Rosenberg PA et al. also reported similar results. ${ }^{23}$ The improved success rate of articaine might be due to its higher lipid solubility, which owes to the thiophene ring of articaine. ${ }^{24}$ On the contrary, a significant difference was found between articaine and lidocaine after buccal infiltration by Ashraf et al. The differences in success rate could certainly be due to potential population differences. ${ }^{28}$ Srinivasan et al. observed a similar difference between articaine and lidocaine, which was significant, whereas Kanaa MD et al. found no significant difference. 8,25

In the present study, $96.67 \%$ of the articaine group and $83.33 \%$ of the lidocaine group had no pain during the endodontic treatment procedure after IANB and buccal infiltration. Though articaine has a slightly higher success rate, within the limitations of this study, no significant difference was found between two local anaesthetic agents (P $<0.05)$. The failure rate may be due to the limited anaesthetic ability to diffuse through the mandibular alveolus's entire thickness. In these situations, other management options like intrapulpal anaesthesia, intraosseous injection, periodontal ligament injection can be used.

\section{CONCLUSIONS}

Using $4 \%$ articaine and $1: 100,000$ dilution of epinephrine, the IANB was much effective than $2 \%$ lidocaine and 1 : 80,000 dilution of epinephrine in producing pulpal 
anaesthesia in mandibular molars suffering irreversible pulpitis. Following buccal infiltration, $4 \%$ articaine performed better than $2 \%$ lidocaine with an overall success rate of $97 \%$, while lidocaine had a success rate of $83 \%$.

Data sharing statement provided by the authors is available with the full text of this article at jemds.com.

Financial or other competing interests: None.

Disclosure forms provided by the authors are available with the full text of this article at jemds.com.

\section{REFERENCES}

[1] Khan S, Hamedy R, Lei Y, et al. Anxiety related to nonsurgical root canal treatment: a systematic review. J Endod 2016;42(12):1726-36.

[2] Konagala RK, Mandava J, Pabbati RK, et al. Effect of pretreatment medication on postendodontic pain: a double - blind, placebo - controlled study. J Conserv Dent 2019;22(1):54-8.

[3] Parirokh M, Abbott PV. Various strategies for pain - free root canal treatment. Iran Endod J 2014;9(1):1-14.

[4] Walton RE, Abbott BJ. Periodontal ligament injection: a clinical evaluation. J Am Dent Assoc 1981;103(4):571-5.

[5] Aggarwal V, Jain A, Kabi D. Anaesthetic efficacy of supplemental buccal and lingual infiltrations of articaine and lidocaine after an inferior alveolar nerve block in patients with irreversible pulpitis. J Endod 2009;35(7):925-9.

[6] Meechan JG. Why does local anaesthesia not work every time? Dental Update 2005;32(2):66-8, 70-2.

[7] Cohen HP, Cha BY, Spangberg LS. Endodontic anaesthesia in mandibular molars: a clinical study. J Endod 1993;19(7):370-3.

[8] Kanaa MD, Whitworth JM, Corbett IP, et al. Articaine Buccal infiltration enhances the effectiveness of lidocaine inferior alveolar nerve block. Int Endod J 2009;42(3):238-46.

[9] Malamed SF, Gagnon S, Leblanc D. A comparison between articaine $\mathrm{HCl}$ and lidocaine $\mathrm{HCl}$ in pediatric dental patients. Pediatr Dent 2000;22(4):307-11.

[10] Heft MW, Parker SR. An experimental basis for revising the graphic rating scale for pain. Pain 1984;19(2):15361.

[11] Hargreaves KM, Keiser K. Local anaesthetic failure in endodontics: mechanisms and management. Endod Topics 2002;1:26-39.

[12] Walton RE, Torabinejad M. Managing local anaesthesia problems in the endodontic patient. J Am Dent Assoc 1992;123(5):97-102.

[13] Wong MK, Jacobsen PL. Reasons for local anaesthesia failures. J Am Dent Assoc 1992;123(1):69-73.
[14] Corbett IP, Ramacciato JC, Groppo FC, et al. A survey of local anaesthetic use among general dental practitioners in the UK attending postgraduate courses on pain control. Br Dent J 2005;199(12):784-7; discussion 778.

[15] McEntire M, Nusstein J, Drum M, et al. Anaesthetic efficacy of $4 \%$ articaine with 1: 100,000 epinephrine versus $4 \%$ articaine with 1: 200,000 epinephrine as a primary buccal infiltration in the mandibular first molar. J Endod 2011;37(4):450-4.

[16] Ashraf H, Kazem M, Dianat 0, et al. Efficacy of articaine versus lidocaine in block and infiltration anaesthesia administered in teeth with irreversible pulpitis: a prospective, randomized, double - blind study. J Endod 2013;39(1):6-10.

[17] Jung IY, Kim JH, Kim ES, et al. An evaluation of buccal infiltrations and inferior alveolar nerve blocks in pulpal anaesthesia for mandibular first molars. J Endod 2008;34(1):11-13.

[18] Claffey E, Reader A, Nusstein J, et al. Anaesthetic efficacy of articaine for inferioralveolar nerve blocks in patients with irreversible pulpitis. J Endod 2004;30(8):568-71.

[19] Tortamano IP, Siviero M, Costa CG, et al. A comparison of the anaesthetic efficacy articaine and lidocaine in patients with irreversible pulpitis. J Endod 2009;35(2):165-8.

[20] Poorni S, Veniashok B, Senthilkumar AD, et al. Anaesthetic efficacy of four percent articaine for pulpal anaesthesia by using inferior alveolar nerve block and buccal infiltration techniques in patients with irreversible pulpitis: a prospective randomized double blind clinical trial. J Endod 2011;37(12):1603-07.

[21] Aggarwal V, Singla M, Miglani S. Comparative evaluation of anaesthetic efficacy of $2 \%$ lidocaine, $4 \%$ articaine and $0.5 \%$ bupivacaine on inferior alveolar nerve block in patients with symptomatic irreversible pulpitis: a prospective, randomized, double - blind clinical trial. J Oral Facial Pain Headache 2017;31(2):124-8.

[22] Whitworth JM, Kanaa MD, Corbett IP, et al. Influence of injection speed on the effectiveness of incisive / mental nerve block: a randomized, controlled, double - blind study in adult volunteers. J Endod 2007;33(10):1149-54.

[23] Rosenberg PA, Amin KG, Zibari Y, et al. Comparison of 4 $\%$ Articaine with 1: 100,000 Epinephrine and $2 \%$ Lidocaine with 1: 100,000 Epinephrine when used as a. supplemental anaesthetic. J Endod 2007;33(4):403-05.

[24] Nagendrababu V, Duncan HF, Whitworth J, et al. Is articaine more effective than lidocaine in patients with irreversible pulpitis? An umbrella review. Int Endod J 2020;53(2):200-13.

[25] Srinivasan N, Kavitha M, Loganathan CS, et al. Comparison of anaesthetic efficacy of $4 \%$ articaine and 2 $\%$ lidocaine for maxillary buccal infiltration in patients with irreversible pulpitis. Oral Surg Oral Med Oral Pathol Oral Radiol Endod 2009;107(1):133-6. 